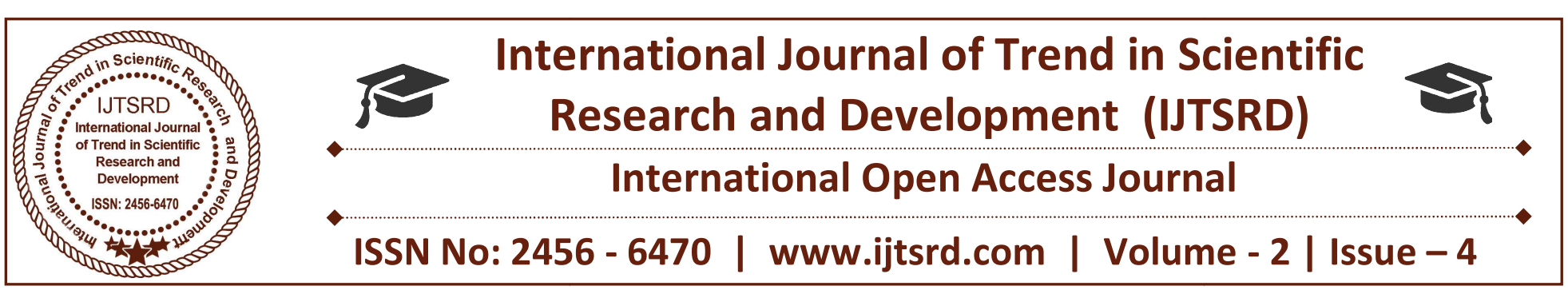

\title{
A Review on Codeigniter
}

\author{
Rohit Jahagirdar \\ PG Student, Affiliated to Department of (MCA), \\ P.E.S.'s Modern College of Engineering, \\ Pune, Maharashtra, India
}

\author{
Yogeshchandra Puranik \\ Asst.Professor, Affiliated to Department of (MCA), \\ P.E.S.'s Modern College of Engineering, \\ Pune, Maharashtra, India
}

\section{INTRODUCTION}

Framework is important for large-scale objectoriented software systems for development. They offer market value for high productivity and low time through design and recycling codes. CodeIgniter is a PHP framework developed by Alice Lab and does not require additional configuration. You do not have to use the command line, it is extremely light that usually provides a rich set of libraries for essential works, as well as provides a simple interface and logical design to access this library. CodeIgniter's face challenges you to search for a framework that works better than codeigner. CodeIgniter uses the MVC approach. CodeIgniter is fully documented. CodeIgniter is a friendly community for users. PHP5 is a Scripting language dock to create a sophisticated, dynamic web-based application; It's top of its friendship with HTML; It's also a great language to honor your OOP's skills, it is tight, safe and the intuitive. Many of us have only server-side language to meet our needs. This makes coding more easier, faster, and user-friendly in PHP. Model / View / Controller (MVC) should study the web development with the best practices that all developers should follow. It's created on linear and easy to use folders configuration. It is open source, easy to configure, customize for its own needs. You can create your own clean URI line in CodeIgniter. For this we create controller, model and view, as well as database to keep information. CodeIgniter is a PHP MVC schema that aims to simplify normal operations while implementing Structured Code so that it is easy to debug, scale, and develop a team. You will compare Codeigniter to another framework in which Zend is not restricted to implementing MVC configurations. It can be seen as negative or positive, all of which depends on us and how you use it. There are many frameworks available and you can do some research to determine what will work best.

\section{Literature Survey}

Our study included different types of strings like "web development assessment" and "web development performance". In conclusion, most of the material is generally evaluated, not about the performance of web development. The search for data was about to evaluate performance and the selection of materials research in this area was not profitable but it was not easy to find. Important It is a good way to find out how to do research in this data and it is often found in an abstract but sometimes in the background. In 2001, Samisa Abesingh, mainly focuse on how the M-V-C and framework techniques makes difference in web development. In this book MVC is a major part of PHP development and is about what it does for web development. In 2001, Mohammed Mustafa analyzes the PHP development model-based MVC framework, in 2001, helping the developers to learn MVC structure more easily. CodeIgniter is an analysis of how MVC based framework are works in performance and coding of user coding. The ability for developers is here to explain how MVC structure helps the development of web applications, how developers can develop more efficient web applications. In 2001, Peter Savacek and John Bartlett understood web performance. He presented how the display can be used and how it is important in the web business. It also shows how testing can be done and how the test can be affected. This paper lets developers know how to manage value and time in web application development. 
In 2003, Lance Tichkosky A. Al. A paper published by A Performance Cooperson of Dynamic Web Technologies, describes how many results of performance, different types of comparative analysis and how they performed. In 2015, David Diaz Clavozo compared the practical Azil Web framework, in which he compared the codiginiter, cakePHPt and the Lorevele Framework. He also reviewed the framework for an effective website development by a developer where he reviewed the various web applications developed using this framework. CodeIgniter is also a MVC based PHP framework, written by Rick Ellis. The CodeIgniter Framework has certain features, e.g. There are no restrictive coding rules, no need Template language learning, small but extensive libraries and complete documentation. These features are suitable for small and medium sized utensils. In CodeIgniter, There is no databaselike object-relational mapping (ORM). Due to the absence of ORM in the CodeIgniter framework, database communication becomes complex and unsafe. There is a client request process in CodeIgniter is as given below:

a. the index.php serves as front controller in the $\mathrm{CI}$, that initializing the base resources needed to run CodeIgniter smoothly.

b. Router examine the HTTP request to determine what should be done with request.

c. If cache file already exists, it's then sent to the browser, by sending normal system execution.

d. Security is loaded Before application controller, HTTP request \& any user submitted data is filtered for security.

e. the Controller loads model, helpers, core libraries and the other resources needed to process the specific request of the user.

$\mathrm{f}$. The finalized View is then rendered and sent to the browser to be displayed. If the caching is enabled, then view is first cached so that on subsequent requests it can be served. Framework is a set of libraries that are organized in architectural design to deliver the speed, accuracy, convenience and consistency in development of such applications, framework contains following elements:
$>$ Architecture

$>$ File library

$>$ Methodology.

If this framework is associated with the word PHP, it can be interpreted as a patterned framework that enables easy web development using PHP language .

\section{Comparison between CodeIgniter and CakePHP:}

\section{In terms of simplicity}

CodeIgniter are considered best for their view of simplicity, when using the CodeIgniter Framework, web development is done in the loading library, the work is done in the controller and pulled in view. Nothing is hidden \& you can see how things get done in CodeIgniter framework. Getting PHP faster, coding was faster, but to learn more, the developer must go to the core. Otherwise, it is a somewhat hard to understand how things work in CodeIgniter.

\section{$>$ Components}

In the CodeIgniter, developers have to create or identify an right plug-ins or tools, despite having numerous classes like FTP,SFTP class. On the other hand, CakePHP has Auth component at the core.

\section{Object-relational mapping (ORM)}

Cake PHP framework follows the ORM technique where in ORM programming that turns data of the different type systems in the database. CodeIgniter doesn't come with ORM, so for the conversion, developers have to rely on the third parties.

\section{Scaffolding}

Both the frameworks are loaded with the scaffolding feature, but it works differently with both the framework. Cake PHP scaffolding enables the developers to define way objects are linked and can be create or break links. Also, developers can define and build application, which can create, update, retrieve and delete objects.

CodeIgniter scaffolding yields as a quickest way to add, modify or remove information from database during web development. 


\section{Code generation}

CodeIgniter, there is no basic ingredients to generate code lies as it won't have any code generation from the console. Sadly, developers have to find different plug-ins.

CakePHP is endowed with Bake console that eases creation of models, controllers, and views. Due to which building a full-fledged application becomes a work of a few minutes.

\section{MVC}

Although both frameworks are working on MVC architecture based, but in the CodeIgniter, model association is absent and developers are allowed to build project even without using MVC that turns the code unsecured and the messy because anyone can place the query without any filtering.

In CakePHP, the project cannot be built without model, so the query to get value from a table with any field is very simple.

\section{Console}

In CakePHP it has this feature, which works great when team of developers is working remotely for web development. The console allows developers to upgrade the DB schema or generate the code, so other users are not allowed to handle the DB straightly. Instead, CI doesn't have the console.

\section{Layout}

CakePHP leverages the default layout where implementing the header, footer or sidebar is easier. While CodeIgniter create the view or layout with the direct approach, which appears like the app was built from the ground up. Plus, CodeIgniter is also provides caching mechanism for view that makes the work easier.

\section{Validation}

Using Model-View-Controller model means data validation is must. In CodeIgniter, set of rules is defined and allocated to validation objects, which validates every data pass in the form of URL or web form. Validation class also automate validation process by displaying the fixed error messages.
In CakePHP, single test for each and every field's variable is validated and declared. For simple application it is good, but for the complex stuff, it becomes cumbersome.

\section{Function calling- auto or not?}

There are some functions available in the CakePHP, which are automatically called, These functions are auto-executed when they pre-defined. In CodeIgniter, no such auto-function exists.

\section{Architecture of CodeIgniter \\ Block Diagram}

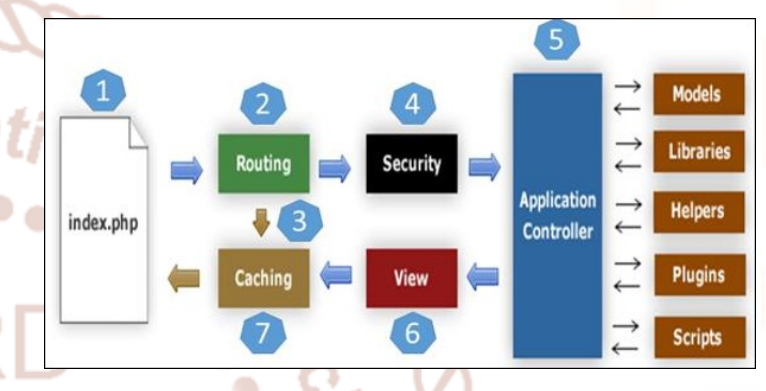

Fig3.1.1 Block Diagram of CodeIgniter

As shown in figure, when Codeigniter has a request, he will go to index page first.

In the step-2, Routing of the website will decided whether to pass this request to the $3^{\text {rd }}$ step for the process of caching or pass this request to the $4^{\text {th }}$ step for performing security check on it.

If the page requested is already available in the Caching, then Routing will pass request directly to the $3^{\text {rd }}$ step and response will go back to the user.

If the requested page doesn't exist in Caching, then Routing will pass the requested page to the $4^{\text {th }}$ step for the purpose of Security checks.

Then Before passing the request to the Application Controller, Security of the submitted data is checked once. only After Security check, Application Controller loads necessary Models, Libraries, Helpers, Plugins, Scripts and pass it on to View.

View will render the given page with the available data and passes it for Caching. As requested page wasn't cached before so it will be cached in Caching, to process this page quickly for future requests.

\section{Directory Structure}


International Journal of Trend in Scientific Research and Development (IJTSRD) ISSN: 2456-6470

below image shows directory structure of $>$ Helpers - In this folder, you can put helper class CodeIgniter.

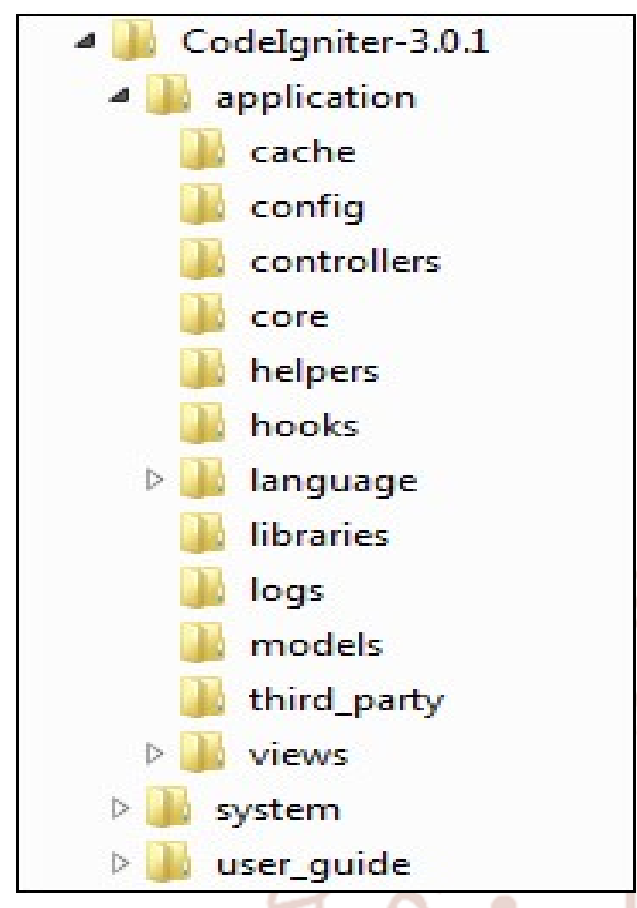

Fig3.2.1. directory Structure of CodeIgniter of your application.

$>$ Hooks - The files in this folder provide a means to tap into and modify the inner workings of the framework without touching the core files.

$>$ Language - This folder contains language related files.

$>$ Libraries - This folder contains files of the libraries developed for your application.

$>\operatorname{Logs}$ - This folder contains log of the system.

$>$ Models - all Database related file will be placed in this folder.

$>$ Third-party - It contains, any plugins, which will be used for your application to perform some function.

Views - Application's HTML files will be placed in this folder which will be displayed in the users browser.

\section{System}

This folder contains CodeIgniter core codes, libraries, helpers and other files, which help make the coding easy for user. These libraries and helpers are loaded and used in web app development for simplicity.

directory structure of CodeIgniter is divided into three folders -

This folder contains all the CodeIgniter code of consequence, organized into various folders -

\section{$>$ System \\ $>$ User guide}

\section{Application}

As name indicates an Application folder contains all the code of your application that you are writing. This is folder where you will develop your project. an Application folder contains several other diffrent folders, which are explained as below -

Cache - This folder contains all the cached pages of the application. These pages will increase overall speed of accessing pages.

$>$ Config - This folder contains various files to configure application. With help of config.php file, user can configure the application. Using database.php file, user can configure the database of application.

$>$ Controllers - This folder holds controllers of your application. It is the very basic part of your application.

$>$ Core - It contains base class of your application.
Core - This folder contains CodeIgniter's core class All of your work will take place in the application folder. Even if your intent is to extend the CodeIgniter core, you have to do it with hooks, and hooks live in the application folder and no need to modify files in this folder.

Database - The database folder contains core database drivers and other database utilities which are essential for accessing database.

Fonts - The fonts folder contains diffrent font related information and utilities.

Helpers - helpers folder contains standard CodeIgniter helpers. (such as date, cookie, and URL helpers)

Language - The language folder contains files related to language.

Libraries - The libraries folder contains standard CodeIgniter libraries (to help you with e-mail, calendars, file uploads, and many more). You can create your own libraries or extend (and even replace) standard ones as per your requirement, but those will be saved in the application/libraries directory to keep them separate from the standard 
CodeIgniter libraries saved in this particular folder.

\section{Characteristics}

1) It is easy and flexible to learn, improve and integrate libraries and helper.

2) Using MVC pattern so that the design of the generated code is more structured and clearly standard.

3) Very friendly URL generated code ignitioner used at least \$_GET and replaced with a URL CodeIgniter works structure that starts with a browser that will be communicated by the controller. The moderator then receives all the requests received from the browser and will reply. For data, the controller will ask for a model and ask to see the UI / Template Controller. When a browser prompts for a web page, the router detects the

controller Which can handle the request. The controller will then use to display the data and will use the model view to display the data. MVC is used to data access and to break business

4)logic from the data presentation and user interaction. Separation was done so that any changes in the presentation logic or business logic does not give effect to each other are

5)complex . MVC separation solution is expected to improve the flexibility and reusability of the application

\section{Advantages and Disadvantages}

\section{Advantages:}

It aims to be able to develop a project faster than you, if you are writing a code from scratch, by providing a rich library of general programs for access to this book, as well as a simple interface and logical structure. CodeIgniter lets you focus your project creatively on lowering the number of codes you need

\section{$>$ Time}

The first and foremost issue that attracts every developer towards the codeigner is its fast response time. CodeIgniter responds very quickly that no framework is available in this world so far as that can give it so fast. CodeIgniter User
Community When you have problems or questions, working is too big. Ready for Frameworks with almost zero configuration.

\section{$>$ Coding}

If you are going to start a new project with custom PHP, then you obviously need to do things like create a database, create configuration files and much more. We will need to connect every database data using the database query, you need to use the functions directly in the functions where necessary. But in the codeigniter, you do not have to worry about such classes and structures.

Just download latest version, download it and set up few things and it's done !!

a. The whole zip comes with 3 folders usually, Application

b. System

c. User Guide

\section{Flexibile, Secure \& User Friendly}

Light Weight, OpenSource and Fast CodeIgniter has rich set of libraries which are easy to write and change it's behaviour.

CodeIgniter is a logical compromise of this library access. Additional libraries are dynamically filled on an additional basis for your additional needs, so the support system is very weak and very fast. Coedigner comes with a fully categorized library so that the necessary web development tasks are usually enabled, such as databases, sending email, validating the data of the form, maintaining sessions, handling images, you do not have to use the command line. There is no need to learn a template language because template parse is optionally available. No need to use any unix commands. Install tools and uploads only in the server directory. CI add / remove your database like this Create tables, new tables, and remove old people using the new database phases library.

CodeIgniter has standard Error Handellin technique CodeIgniter keeps site secure from $\mathrm{CSRF} / \mathrm{XSRF}$ Attacks and SQL injection by using built in classes and libraries.

CodeIgniter has Cache library 
$>$ Uses M-V-C

Though it encourages MVC, but does not force it on you. CodeIgniter uses the Model-ViewController approach, which allows great separation between logic and presentation.

Separation of code has been very easy in Codeigniter.

\section{Generates Clean URLs}

The URLs generated by CodeIgniter are clean and search-engine friendly. CodeIgniter uses a segment-based approach Rather than using the standard "query string" approach to URLs.

\section{Extensible}

The system can be easily extended through the use of your own libraries, helpers, or through class extensions. CodeIgniterassists the developer to build core libraries for the system and enables you to integrate your own existing scripts with database.

And to improve your productivity it also supports for third-party addons/plugins for additional functionality.

\section{Built in security tools}

Unserving all global variables without registering PHP Register globals Directive Close Magic_quotes_runtime Directive during system initialization Enable Cookie Encryption Conversation session data with database exits Auto SQL queries

\section{Configuration and Customizable}

This aspect helps the developers to create what is needed for web-based development. In addition, this framework is easy to structure and customize files.

\section{Disadvantages}

$>$ Its PHP based only and not very objectoriented in some parts

$>$ PHP4 legacy code,

$>$ Company-driven instead of communitydriven,

$>$ Irregular releases,
> Framework itself has no built-in ORM (only via 3rd party solutions).

\section{Conclusion}

The main purpose of this review paper is to establish the basic concepts of codeigniter framework and the CodeIgniter.

While selecting the big project Codeigniter study paper you must now have a superior perception of the Codeigniter mechanism. Find out how to set it up Find out how to create models, views and controls along with code designers, libraries with all designs, and identify how to send and use it to production.

\section{References}

Books:

1) Programming with CodeIgniter MVC By By Eli Orr, Yehuda Zadik

\section{Links:}

1) https://www.esds.co.in/blog/what-is-code-igniterand-what-are-its-advantages-and-disadvantages/

2) https://Www.angularminds.com/blog/article/codei gniter-advantages-and-disadvantages.html

3) https://www.tutorialspoint.com/mvc_framework/ mve framework introduction.html

4) https://en.wikipedia.org/wiki/CodeIgniter

5) https://www.brainvire.com/To-10-differencesbetween-codeIgniter-and-cakephp

6) http://www.phpframeworks.com/

\section{Research Papers:}

1) International Journal of Research in Computer \& Information Technology (IJRCIT), Vol. 1, Special Issue 2, July-2016

2) THE MVC FRAMEWORK-CODEIGNITER International Journal of Novel Research and Development (www.ijnrd.org) 